\title{
Bryostatin I inhibits growth of breast cancer cells through the inhibition of synuclein-A expression
}

\author{
Jun-Xia Sun, Yan Yan, Jian-Hong Xia and Li-Qing Zhou \\ Department of Radiotherapy, The Second People's Hospital of Huaian, Jiangsu 223-002, China.
}

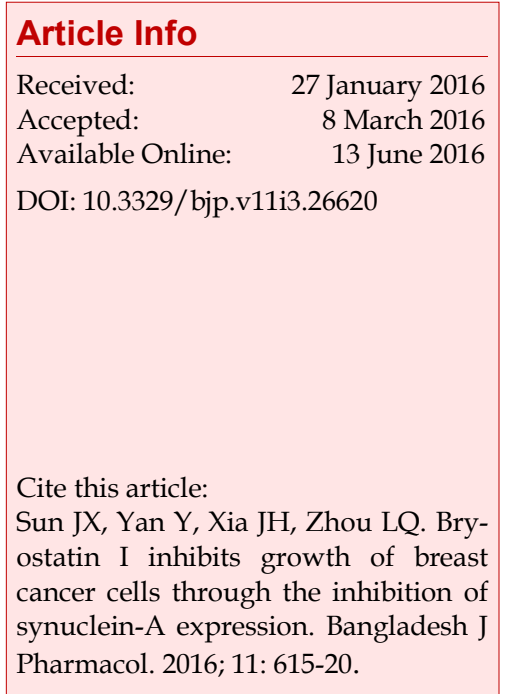

\begin{abstract}
The present study was aimed to investigate the effect of bryostatin I on the expression of synuclein-A in breast cancer cells. Western blot analysis showed a significant $(\mathrm{p}<0.005)$ reduction in the expression of synuclein-A from a concentration of $20 \mu \mathrm{M}$ in H3922 cells. The inhibitory effect of bryostatin I on synuclein-A expression was further confirmed by the treatment of H3922 cells with known synuclein-A inhibitor, cytokine oncostatin M. Bryostatin I treatment of H3922 cells also significantly increased their sensitivity to the taxol. Incubation of the cells with $25 \mu \mathrm{M}$ concentration of bryostatin I followed by treatment with $0.5 \mu \mathrm{M}$ concentration of taxol induced apoptosis in $89 \%$ cells compared to $9 \%$ cells in the taxol alone treated cultures. Treatment of the H3922 cells with bryostatin I at $25 \mu \mathrm{M}$ concentration led to a significant increase in the activation of histone $\mathrm{H} 1$ protein. The results from MTT assay showed a significant decrease in the cell viability from $10 \mu \mathrm{M}$ concentration of bryostatin I. Thus, bryostatin I inhibits the growth of breast cancer cells through inhibition of synuclein-A expression and can be used for breast cancer treatment.
\end{abstract}

\section{Introduction}

Breast cancer is a major challenge to the clinicians today throughout the world because of an incidence of more than 1 million new cases and more than 370,000 deaths annually.

Treatment of the breast cancer in initial stage is highly desired as the advanced disease will eventually develop resistance to treatment (Ali and Coombes, 2002).

The expression of the gene, synuclein- $\mathrm{A}$ is associated with the development and progress of breast cancer (Ji et al., 1997). Synuclein-A is highly expressed in the cancer cells resistant to chemotherapeutic agents, possessing higher invasive and migration potential but is not found in the normal breast cancer cells (Bruening et al., 2000; Wu et al., 2003). Analysis of the effects of synuclein-A led to understanding of its role in promoting carcinoma cell proliferation, increasing invasive and migratory potential (Liu et al., 2000; Lu et al., 2002). Synuclein-A exhibits its effect through a mitotic checkpoint kinase in the breast carcinoma cells (Gupta et al., 2003).

The chemotherapeutic agents used for the treatment of breast cancer including taxol induce cell cycle arrest in the mitotic phase and finally lead to apoptosis (Blajeski et al., 2002; Shin et al., 2003). However, it has been observed that synuclein-A prevents the cancer cells from cell cycle arrest in the mitotic phase leading to drug resistance (Pan et al., 2002). Therefore, inhibition of the synuclein-A expression can be of immense importance for the treatment of breast cancer either directly or by facilitating the action of other chemotherapeutic agents.

Bryostatin I exhibits remarkable biological activities in the cancer therapy through alterations in the function of apoptosis factors (Wall et al., 1999), reversal of 
multidrug resistance (Spitaler et al., 1998), and activation of the immune system (Oz et al., 2000). The efficacy of bryostatin I varies in different types of cancers. Various studies have demonstrated that it enhances the efficiency of other oncolytics against various types of cancers (Dowlati et al., 2003). Bryostatin I and its synthetic analogs have shown promising results in the treatment of cancer at very low doses (Shaha et al., 2009). In the present study effect of bryostatin I on expression of synuclein-A and viability of cells in breast cancer cells was investigated. Bryostatin I inhibits the expression of synuclein-A and viability of breast cancer cells.

\section{Materials and Methods}

\section{Reagents and antibody}

Bryostatin I was purchased from the Sigma-Aldrich (USA). The antibodies against Cdc2 and synuclein-A were purchased from Santa Cruz Biotechnology (USA).

\section{Cell lines and culture}

H3922 cell line was supplied by the American Type Culture Collection (USA). The cells were cultured for 24 hours in RPMI-1640 medium in an incubator with humidified atmosphere of $5 \% \mathrm{CO}_{2}$ at $37^{\circ} \mathrm{C}$. The medium contained fetal bovine serum $(10 \%)$.

\section{Cell viability assay (Video Clip)}

The effect of synuclein-A on the viability of H3922 breast cancer cells was examined by MTT assay. Briefly, the cells growing exponentially were collected and put into 96-well plates at a density of $2.5 \times 10^{6}$ cells per well. After incubation for a period of 24 hours at $37^{\circ} \mathrm{C}$ temperature, different concentrations of synuclein-A (5, $10,15,20,25$ and $30 \mathrm{M}$ ) were added to the wells and incubation was continued for 48 hours. Then, to each well of the plate $20 \mu \mathrm{L}$ of MTT solution was added and incubation of the plates was performed for 4 hours more. Following incubation, the supernatant was removed and to each well was added $150 \mu \mathrm{L}$ DMSO. For each of the well optical density was recorded at 470 $\mathrm{nm}$ using a microplate reader (BioRad Instruments, USA).

\section{Apoptosis analysis}

The cells were cultured in medium supplemented with dimethyl sulfoxide or various concentration of bryostatin I for 48 hours. Following incubation, H3922 cells were subjected to annexin V-EGFP staining using Apoptosis Detection Kits (Medical and Biological Laboratories, Japan) as per the manual protocol. FACScan (Becton-Dickinson Immunocytometry Systems, USA) was used for the analysis of positively stained cells.

\section{Cell cycle analysis using flow cytometry}

Breast cancer cell after treatment with bryostatin I or control cells were collected, washed twice with PBS and put $\left(10^{6} / \mathrm{mL}\right)$ in a hypotonic fluorochrome solution (50 $\mathrm{mg} / \mathrm{mL}$ propidium iodide in $0.1 \%$ sodium citrate plus $0.1 \%$ Triton X-100; Sigma-Aldrich). After incubation for 2 hours at $50^{\circ} \mathrm{C}$ under dark conditions, FACScaliber flow cytometer (BD Biosciences, USA) with ModFIT cell cycle analysis software version 2.01.2 (BD Biosciences) was used for analysis of propidium iodide fluorescence a. The experiments were performed in triplicates for each condition.

\section{Analysis of Cdc2 kinase activity}

The cell lysate ( $1 \mathrm{mg}$ ) was subjected to incubation with rabbit monoclonal antibody against Cdc 2 at $4^{\circ} \mathrm{C}$ for 2 hours. $20 \mu \mathrm{L}$ of sepharose A protein was added to cell lysates followed by dilution with $2 x$ propidium iodide buffer. After dilution, the samples were incubated at $4^{\circ} \mathrm{C}$ for 2 hours and then centrifuged. The $1 \mathrm{x}$ propidium iodide buffer (1\% Triton X-100, $10 \mathrm{mM}$ Tris, $\mathrm{pH} 7.4$, $0.5 \%$ NP-40, $150 \mathrm{mM} \mathrm{NaCl}, 1 \mathrm{mM}$ EDTA, 1 mM EGTA $\mathrm{pH}$ 8.0) supplemented with protease inhibitor cocktail was used for washing the complex. The pellets washed with kinase buffer $(10 \mathrm{mM}$ Tris $\mathrm{pH} 7.4,150 \mathrm{mM} \mathrm{NaCl}$, $10 \mathrm{mM} \mathrm{MgCl}$, and $0.5 \mathrm{mM} \mathrm{DTT}$ ) were centrifuged, incubated with $30 \mu \mathrm{L}$ of the kinase buffer containing 15 $\mu \mathrm{M}$ ATP, $5 \mu \mathrm{Ci}$ [32P]ÁATP, and $8 \mu \mathrm{g}$ histone H1. SDS sample buffer was added to quench the reaction of kinase. SDS-PAGE was used for the isolation of phosphorylated $\mathrm{H} 1$ which was then detected by Phospholmager.

\section{Western blot analysis}

The MMP-2 and MMP-9 activities in the breast cancer cells were determined by a standard Western blot analysis. H3922 breast cancer cells that were treated with various concentrations of bryostatin I for 48 hours. The cells were then treated with cell lysis buffer under ice-cold conditions. The BCA Protein Quantification kit (Joincare Biosciences, China) was used for determination of protein concentration in the cell lysates according to the manufacturer's instructions. Separation of the proteins was achieved on the SDS-polyacrylamide gel by electrophoresis (PAGE). The nitrocellulose membranes on which proteins were transferred were incubated with rabbit polyclonal primary antibodies against MMP-2, MMP-9 and GAPDH (1:1,000 dilution) at $4^{\circ} \mathrm{C}$ for overnight. Following incubations the membranes washed with PBS and subsequently incubated with anti-rabbit secondary antibodies conjugated with horseradish peroxidase (1:20,000 dilution) for 2 hours. The enhanced chemiluminescence reagent (Amersham Pharmacia Biotechnology, USA) was used for detection of the blots and analysis was performed using Quantity One 1D Analysis software (version 4.4; BioRad). 


\section{Statistical analysis}

The data presented as the mean \pm standard error of the mean (SEM). The data analysis for statistical significance was performed using an analysis of variance (ANOVA). The statistically significant differences were considered at $\mathrm{p}<0.05$.

\section{Results}

\section{Bryostatin I inhibits expression of synuclein-A}

Bryostatin I treatment of H3922 breast cancer cells led to the inhibition of synuclein-A expression in a concentration dependent manner. H3922 cells were incubated with 5, 10, 15, 20, 25 and $30 \mu \mathrm{M}$ concentrations of bryostatin I for 48 hours. The results from Western blot analysis revealed a significant $(p<0.005)$ reduction in the expression of synuclein-A from a concentration of $20 \mu \mathrm{M}$ in H3922 cells (Figure 1). The inhibitory effect of bryostatin I on synuclein-A expression was further confirmed by the treatment with known synuclein-A inhibitor, cytokine oncostatin $\mathrm{M}$. Treatment of the $\mathrm{H} 3922$ cells with $0.5 \mu \mathrm{M}$ concentration of cytokine oncostatin $\mathrm{M}$ led to a significant reduction in the expression of synuclein-A.

Bryostatin I increases the sensitivity of $H 3922$ cells to taxol

The results from Western blot analysis showed that treatment of H3922 cells with bryostatin I significantly increased their sensitivity to taxol. Incubation of H3922 cells with $25 \mu \mathrm{M}$ concentration of bryostatin I followed by treatment with $0.5 \mu \mathrm{M}$ concentration of taxol

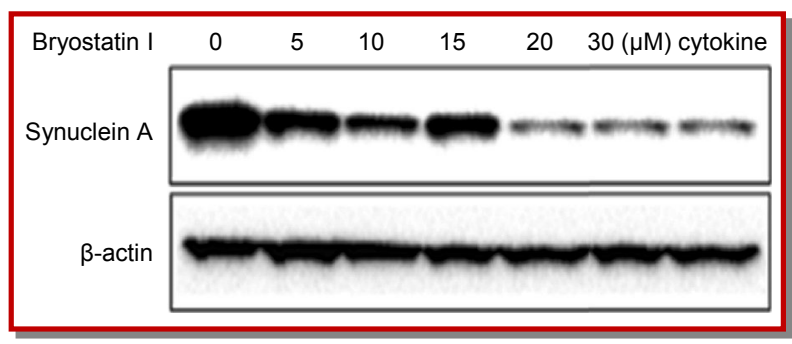

Figure 1: Inhibition of synuclein-A expression by bryostatin I treatment in H3922 breast cancer cells in a concentration dependent manner. Cytokine oncostatin $\mathrm{M}$ also inhibits the expression of synuclein-A in H3922 cells. The cells were treated with $5,10,20,25$ and $30 \mu \mathrm{M}$ concentrations of bryostatin I and $0.5 \mu \mathrm{M}$ concentration of Cytokine oncostatin M for 48 hours and then examined by Western blot assay

induced apoptosis in $89 \%$ cells compared to $9 \%$ cells in the taxol treated cultures (Figure 2).

\section{Effect of bryostatin I on viability of H3922 cells}

Treatment of H3922 cells with bryostatin I for 48 hours showed reduction in the cell viability in concentration dependent manner. The cells were incubated with various concentrations $(5,10,20,25$ and $30 \mu \mathrm{M})$ of bryostatin I for 48 hours and then examined using MTT assay. The results showed a significant decrease in the cell viability from $10 \mu \mathrm{M}$ concentration of bryostatin I. The cell viability was reduced to $2.5,12.6,34.1,59.9$ and $87.2 \%$ on treatment with $5,10,20,25$ and $30 \mu \mathrm{M}$ concentration of bryostatin I for 48 hours compared to $2.0 \%$ in the control (Figure 3).

Effect of bryostatin I on activation of histone H1 protein

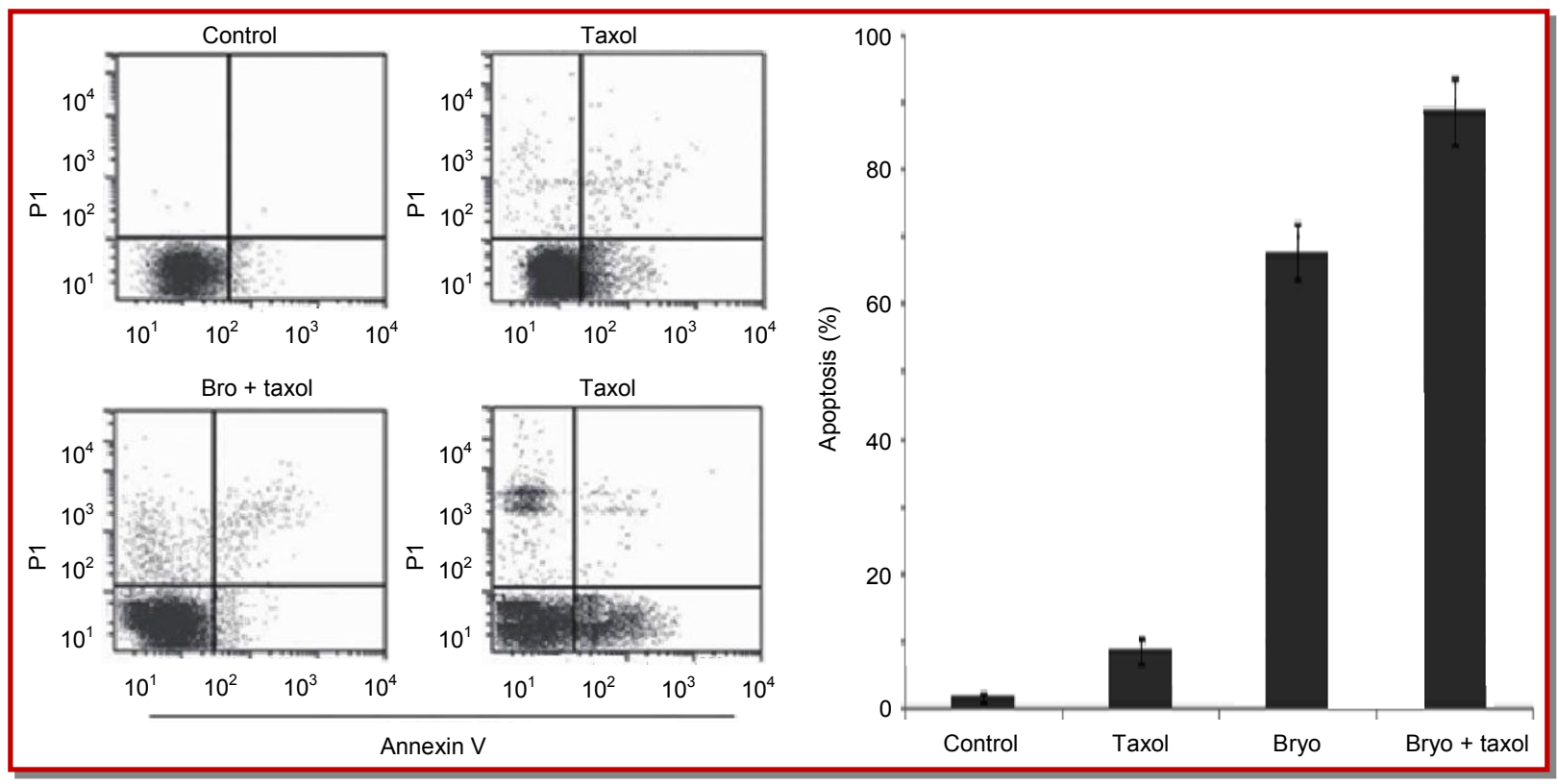

Figure 2: Bryostatin I increased the sensitivity of H3922 cells to taxol. The cells after incubation with taxol alone or pre-treatment with bryostatin I followed by incubation with taxol were analyzed of apoptosis induction 


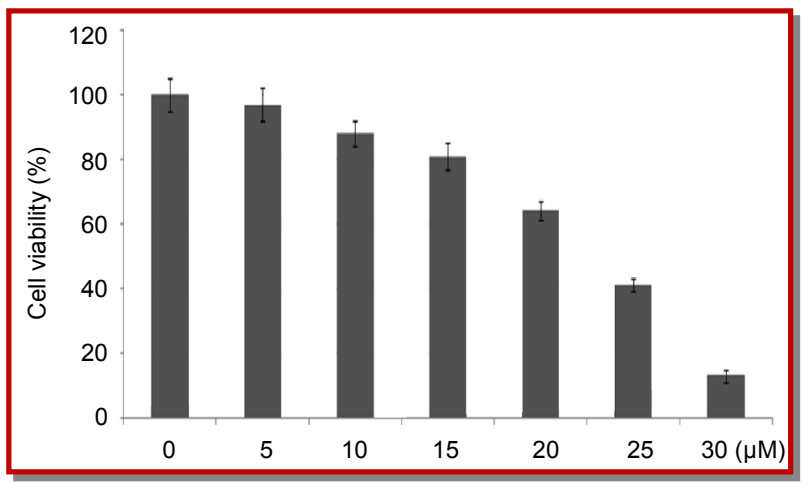

Figure 3: Inhibition of $\mathrm{H} 3922$ breast cancer cell viability by bryostatin I. The cells were treated with 5, 10, 20, 25 and $30 \mu \mathrm{M}$ concentration of bryostatin I or with DMSO alone for 48 hours followed by viability analysis using MTT assay. The experiments for each of the concentration were performed in triplicates

Treatment of the H3922 cells with bryostatin I at $25 \mu \mathrm{M}$ concentration led to a significant $(\mathrm{p}<0.002)$ increase in the activation of the histone $\mathrm{H} 1$ protein. The phosphorylation of the histone $\mathrm{H} 1$ was not observed in the control H3922 cells (Figure 4).

\section{Effect of bryostatin I on the cell cycle distribution}

Bryostatin I treatment of H3922 cells at a concentration of $25 \mu \mathrm{M}$ significantly $(\mathrm{p}<0.002)$ enhanced the population of cells in the G1 phase compared to the control cells. The increase in population of H3922 cells in the G1 phase was accompanied by a simultaneous reduction in G2/M phase. The population of $\mathrm{H} 3922$ cells in the G1 phase was increased from 34.8 to $76.5 \%$ while as that in the G2/M phase was decreased from 58.3 to $11.6 \%$ on treatment with $25 \mu \mathrm{M}$ concentration of bryostatin I for 48 hours (Figure 5).

\section{Inhibition of MMPQ2 and MMP 29 level in H3922 cells by bryostatin I}

Bryostatin I treatment significantly inhibits the expression of MMP-2 and MMP-9 inH3922 cells. Gelatin zymography revealed that the expression of MMP-2 activity was reduced from $64.2 \pm 4.3$ to $16.3 \pm 2.7 \%$ with the increase in concentration of bryostatin I from 5 and $25 \mu \mathrm{M}$. Similarly, the level of MMP-9 was found to be $69.5 \pm 5.1$ and $37.8 \pm 3.4 \%$ at 5 and $25 \mu \mathrm{M}$ concentrations of bryostatin I, respectively (Figure 6).

\section{Discussion}

The current study demonstrates the effect of bryostatin I on the viability of H3922 breast cancer cells. Bryostatin I treatment caused inhibition of H3922 cell viability through suppression of synuclein-A expression and induction of apoptosis.

Synuclein-A is an oncogenic protein which promotes

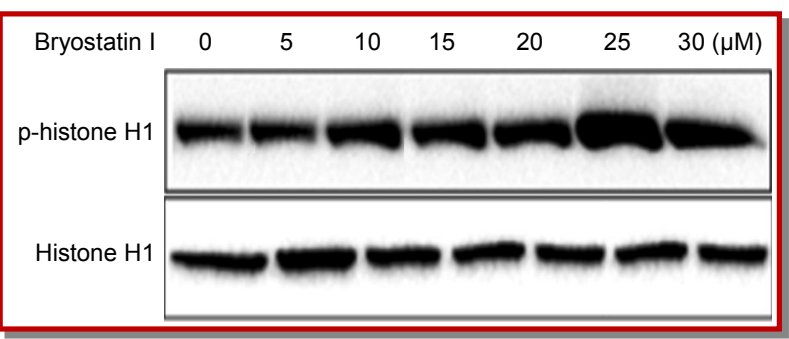

Figure 4: Bryostatin I treatment inhibits the expression of histone $\mathrm{H} 1$ protein. The cells were incubated with $25 \mu \mathrm{M}$ concentration of bryostatin I for 48 hours. After incubation phosphorylation of the histone $\mathrm{H} 1$ protein was analyzed using Western blot assay

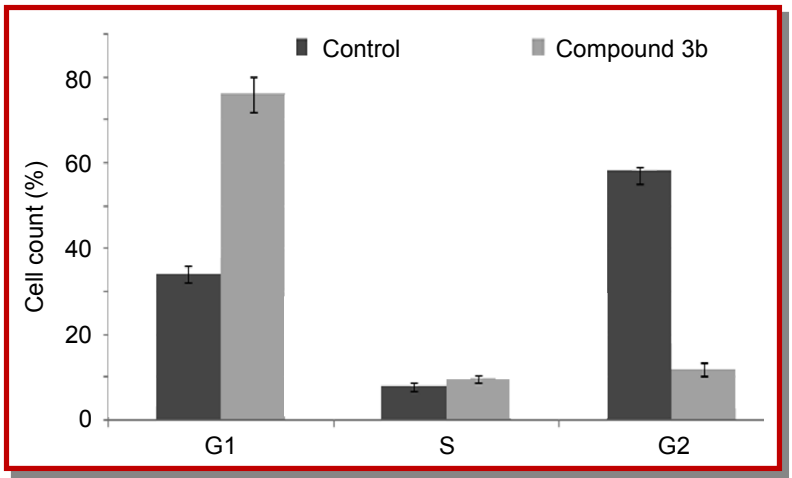

Figure 5: Effect of bryostatin I on distribution of H3922 cells in cell cycle. The cells were treated with bryostatin I and then analyzed by flow cytometry. Bryostatin I treatment increased the population of cells in G1 phase with subsequent reduction in $\mathrm{G} 2 / \mathrm{M}$ phase

proliferation, enhances invasive and migratory potential breast cancer cells (Liu et al., 2000; Lu et al., 2002). Its expression also results in the development of resistance to various chemotherapeutic agents (Gupta et al., 2003; Inaba et al., 2005). In the current study treatment of H3922 cells with bryostatin I caused a significant decrease in the expression of synuclein-A. The reduction of synuclein-A expression by bryostatin I treatment was concentration dependent. The inhibitory effect of bryostatin I on expression of synuclein-A was further confirmed by treatment with its known inhibitor, cytokine (Liu et al., 2000). Treatment of H3922 cells with bryostatin I significantly increased their sensitivity to anti-cancer drugs. Bryostatin I treatment of the cells followed by incubation with taxol induced apoptosis in significantly higher proportion of cells compared to the taxol treated cells. Treatment of H3922 cells with bryostatin I showed reduction in the cell viability in concentration dependent manner using MTT assay. The results demonstrated a significant reduction in the cell viability by bryostatin I treatment.

In H3922 cells treatment with bryostatin I led to a significant $(p<0.002)$ enhancement in the activation of the histone $\mathrm{H} 1$ protein. The phosphorylation of the histone H1 was not observed in the control H3922 cells. Bryostatin I treatment of H3922 cells significantly 


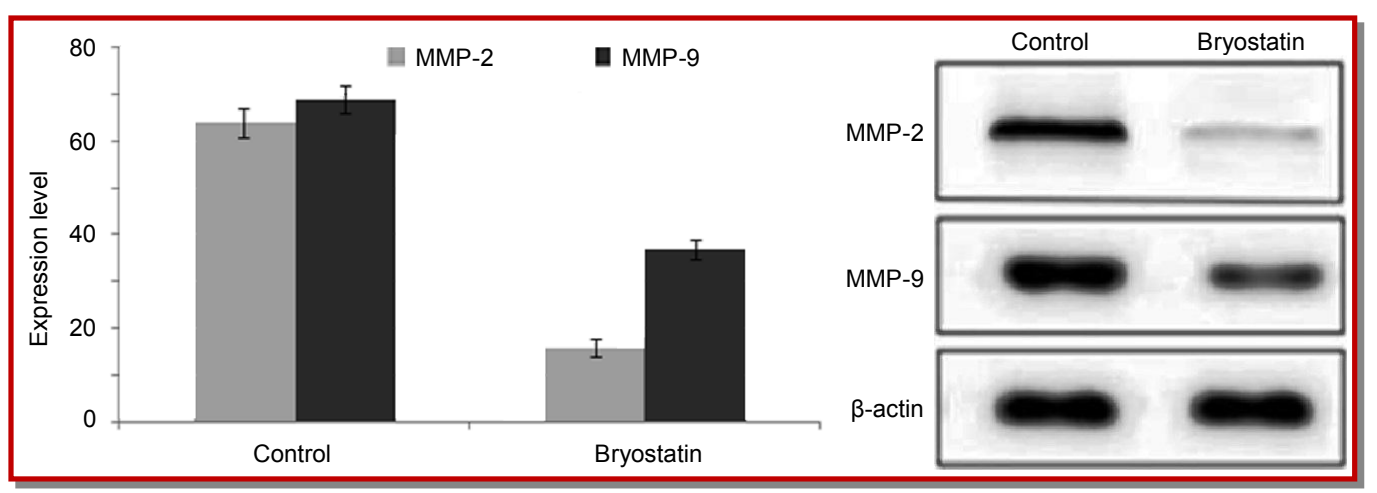

Figure 6: Effect of bryostatin I on the activity of matrix metalloproteins. H3922 cells after incubation with bryostatin I for 48 hours or DMSO as control were examined for the expression of MMP-2 and MMP-9 by Western blot assay

$(p<0.002)$ enhanced the population of cells in the G1 phase compared to the control cells. The increase in population of $\mathrm{H} 3922$ cells in the G1 phase was accompanied by a simultaneous reduction in G2/M phase. Matrix metalloproteinases are the most potent factors associated with the development of resistant cancer and its metastasis ( $\mathrm{Li}$ et al., 2003). It has been demonstrated that inhibition of the expression of MMP2 and MMP-9 reduces the migratory and invasive potential of the cancer cells (Blajeski et al., 2002). In the present study bryostatin I treatment significantly inhibits the level of expression of MMP-2 and MMP-9 in H3922 cells. Gelatin zymography revealed that the expression of MMP-2 activity was reduced to $16.3 \pm$ $2.7 \%$ at $25 \mu \mathrm{M}$ concentration of bryostatin I. Similarly, the expression of MMP-9 was found to be $37.8 \pm 3.4 \%$ at $25 \mu \mathrm{M}$ concentrations of bryostatin I.

\section{Conclusion}

Bryostatin I treatment inhibits the viability and induces apoptosis in breast cancer cells through suppression of synuclein-A expression, MMP-2 and MMP-9 expression and can be used for its treatment.

\section{References}

Ali S, Coombes RC. Endocrine-responsive breast cancer and strategies for combating resistance. Nat Rev Cancer. 2002; 2: 101-12.

Bruening W, Giasson B, Klein-Szanto J, Lee V, Trojanowski J, Godwin A. Synucleins are expressed in the majority of breast and ovarian carcinomas and in preneoplastic lesions of the ovary. Cancer 2000; 88: 2154-63.

Blajeski AL, Phan VA, Kottke TJ, Kaufmann SH. G(1) and G(2) cell-cycle arrest following microtubule depolymerization in human breast cancer cells. J Clin Invest. 2002; 110: 91-99.

Dowlati A, Lazarus HM, Hartman P, Jacobberger JW, Whitacre C, Gerson SL, Ksenich P, Cooper BW, Frisa PS, Gottlieb M, Murgo AJ, Remick SC. Phase I and correlative study of combination bryostatin I and vincristine in relapsed B-cell malignancies. Clin Cancer Res. 2003; 9: 5929-35.

Gupta A, Inaba S, Wong OK, Fang G, Liu J. Breast cancer specific gene 1 interacts with the mitotic checkpoint kinase BubR1. Oncogene 2003; 22: 7593-99.

Inaba S, Li C, Shi YE, Song DQ, Jiang JD, Liu J. Synuclein gamma inhibits the mitotic checkpoint function and promotes chromosomal instability of breast cancer cells. Breast Cancer Res Treat. 2005; 94: 25-35.

Ji H, Liu YE, Jia T, Wang M, Liu J, Xiao G, Joseph BK, Rosen C, Shi YE. Identification of a breast cancer-specific gene, BCSG1, by direct differential cDNA sequencing. Cancer Res. 1997; 57: 759-64.

Liu J, Spence MJ, Zhang YL, Jiang Y, Liu Y, Shi Y. Transcriptional suppression of synuclein gamma (SNCG) expression in human breast cancer cells by the growth inhibitory cytokine oncostatin M. Breast Cancer Res Treat. 2000; 62: 99-107.

Li JN, Song DQ, Lin YH, Hu QY, Yin L, Bekesi G, Holland JF, Jiang JD. Inhibition of microtubule polymerization by $3 \mathrm{~b}$ romopropionylamino benzoylurea (JIMB01), a new cancericidal tubulin ligand. Biochem Pharmacol. 2003; 65: 1691-99.

Lu A, Zhang F, Gupta A, Liu J. Blockade of AP1 trans activation abrogates the abnormal expression of breast cancer-specific gene 1 in breast cancer cells. J Biochem. 2002; 12: $31364-72$.

Oz HS, Hughes WT, Rehg JE, Thomas EK. Effect of CD40 ligand and other immunomodulators on Pneumocystis carinii infection in rat model. Microb Pathog. 2000; 29: 187-90.

Pan ZZ, Bruening W, Giasson BI, Lee VM, Godwin AK. Gamma-synuclein promotes cancer cell survival and inhibits stress- and chemotherapy drug-induced apoptosis by modulating MAPK pathways. J Biol Chem. 2002; 277: 3505060.

Spitaler M, Utz I, Hilbe W, Hofmann J, Grunicke HH. PKCindependent modulation of multidrug resistance in cells with mutant (V185) but not wild-type (G185) p-glycoprotein by bryostatin I. Biochem Pharmacol. 1998; 56: 861-69.

Shaha SP, Tomic J, Shi Y, Pham T, Mero P, White D, He L, Baryza JL, Wender PA, Booth JW, Spaner DE. Prolonging microtubule dysruption enhances the immunogenicity of chronic lymphocytic leukaemia cells. Clin Exp Immunol. 
2009; 158: 186-98.

Shin HJ, Baek KH, Jeon AH, Park MT, Lee SJ, Kang CM, Lee HS, YooSH, Chung DH, Sung YC, McKeon F, Lee CW. Dual roles of human BubR1, a mitotic checkpoint kinase, in the monitoring of chromosomal instability. Cancer Cell. 2003; 4: 483-97.

Wall NR, Mohammad RM, Al-Katib AM. Bax: Bcl-2 ratio modulation by bryostatin I and novel anti-tubulin agents is important for susceptibility to drug induced apoptosis in the human early pre-B acute lymphoblastic leukemia cell line, Reh. Leuk Res. 1999; 23: 881-88.

Wu K, Weng Z, Tao Q, Lin G, Wu X, Qian H, Zhang Y, Ding X, Jiang Y, Shi YE. Stage-specific expression of breast cancer specific gene gamma-synuclein. Stage-specific expression of breast cancer-specific gene gamma-synuclein. Cancer Epidemiol Biomarkers Prev. 2003; 12: 920-25.

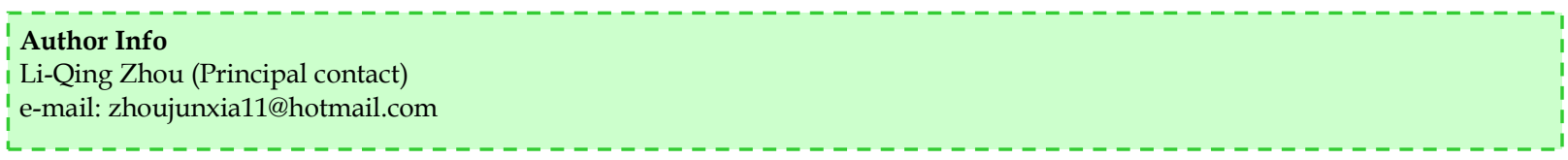




\section{Your feedback about this paper}

1. Number of times you have read this paper 0

2. Number of times you have seen the video clip 0

3. Quality of paper Click

4. Your comments

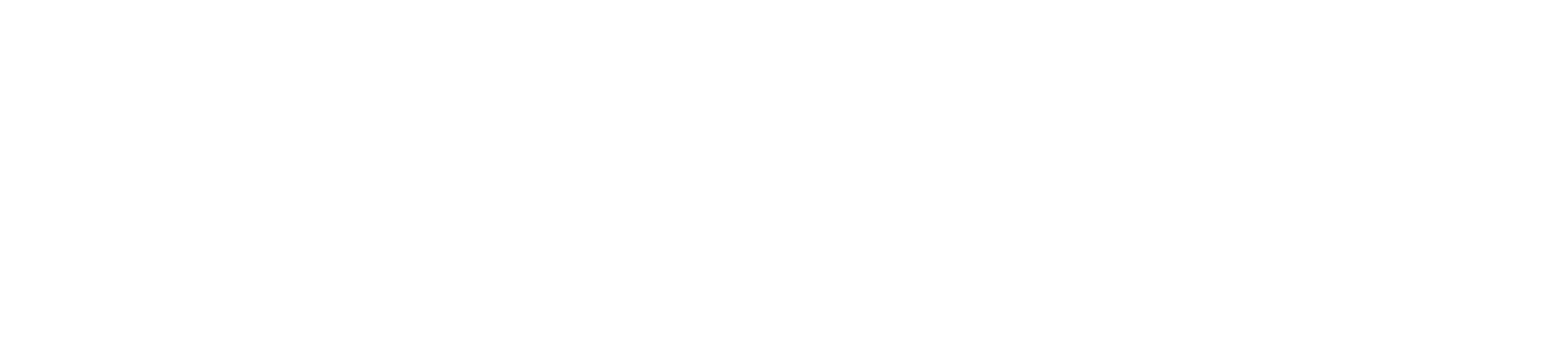

